\title{
PRESENT STATUS OF THE DETERMINATION OF THE CONSTANT OF TOTAL RADIATION FROM A BLACK BODY
}

By W. W. Coblentz

CONTENTS

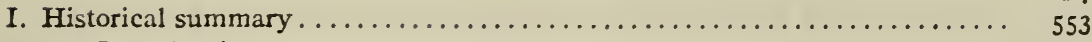

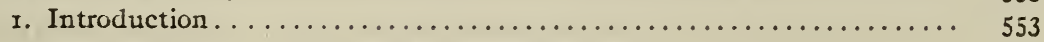

2. The bolometric method of electric compensation ............. 554

3. The thermometric method with "black" receivers.............. 560

4. Indirect and substitution methods....................... 564

II. The present determination of this constant.................. 568

I. Correction for lack of blackness of the radiator................ 570

2. Correction for atmospheric absorption ................... 573

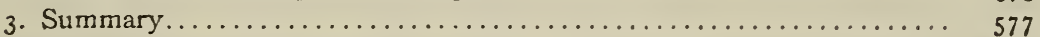

Note I: On standards of radiation............................. 580

\section{HISTORICAL SUMMARY}

\section{INTRODUCTION}

In the present summary of the work on radiation constants it seems desirable to inquire rather critically into the various methods employed in order to find the causes of the discrepancies in the results obtained. 'The past few years have been very productive of researches, employing a variety of methods for determining the constant, $\sigma$, of total radiation." Each method has some defect, but in some cases this is negligible in comparison with the accidental errors of experimentation. The evaluation of radiant energy in absolute measure is accomplished by substitution methods; and the fault to be found with the various methods thus far employed is that they are unsymmetrical in their application. What is needed is some sort of calorimeter in

\footnotetext{
1 The Secfan-Boltamann law states that the total radiation cumatiag from a uniformly heated enclosure, or so-called black body, is proportiossal to the fourth puwer of the absulute temperature. "That is to say, the total radiation emitted is $R=\sigma T$ ', where o is the cuellicient or "Stefau-Boltzmann constant"

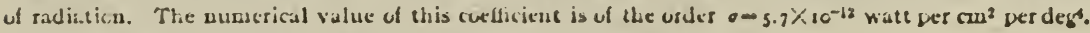
In the tert only the nurnerical value is yucted, e. $\mathrm{s}, 0-5 \mathrm{sa}$.
} 
which the energy recovered can be compared with the energy supplied. The Abbot pyrheliometer, with proper modifications, seems the most feasible method; or a bolometer fashioned somewhat after the methods employed by Puccianti so that it can be used also as the inner parts of a thermometer, thus making the two methods interchangeable. In view of the fact that some of these suggestions are modifications of previous methods which are in the process of development by the writer, and have not been thoroughly tested as to their general applicability, no further comment need be made thereon.

It will be noticed that in many experiments the radiators were operated at the temperatures which were too low to properly eliminate the correction for temperature (radiation) of the shutters, diaphragms, etc.; and also for the losses by air conduction in the receiver. On the other hand, some experimenters used radiators operated at a high temperature, thus obviating these difficulties; but then the receiver was a sluggishly-acting instrument which could not be properly calibrated. To Féry is due the credit for abandoning the idea of using a radiator heated to $100^{\circ} \mathrm{C}$, and adopting a radiator heated to $1000^{\circ} \mathrm{C}$. or higher. In this manner the radiation to be measured is far in excess of the small disturbing factors, such as radiation from shutters, diaphragms, etc.

\section{THE BOLOMETRIC METHOD OF ELECTRIC COMPENSATION}

Kurlbaum ${ }^{2}$ was the first to employ a method for determining the constant of total radiation which is free from the gross experimental errors that are inherent in the work.

The principle of the method is as follows: Three branches of a Wheatstone bridge (bolometer) consist of thick manganin wires which are not affected by a change in current through the bridge. The fourth branch consists of thin bolometer platinum, the resistance of which is affected by a change in current in the bridge. Starting with the bridge balanced, the bolometer branch of thin platinum is exposed to the radiation from a black body at $100^{\circ} \mathrm{C}$, and the change in resistance (or galvanometer deflection) is noted. With the bolometer branch shielded from radiation the bridge

Kurlbaum, Wied. Awn., 65, D. 746; 1898 . 
current is varied until the change in resistance in the bolometer branch is equal to that attained when exposed to radiation. In other words, the bridge current is increased by a sufficient amount to produce the same galvanometer deflection as was caused by radiation falling on the bolometer strip. From a knowledge of the change in the bridge current, the bolometer resistance, etc., Kurlbaum was enabled to compute the energy input. He used two very different surface bolometers and found very concordant values. He found a value of $\sigma=5.32$. In a recent communication $^{3}$ he makes a correction of 2.5 per cent for loss by reflection from the platinum black surfaces of the bolometer. This gives a value of $\sigma=5.45$. Recently the reflecting power of platinum black $^{4}$ has been examined, and it was found that, using the blackest obtainable deposits, the reflecting power is almost 2 per cent for wave lengths at 8 to $9 \mu$. An examination of six surface bolometers (I 2 branches or 24 surfaces of about 3 by $4 \mathrm{~cm}$ area), which were recently purchased abroad, showed that all of them had microscopically small bright patches of bare platinum, and that none of them were as black as the samples examined. From this it appears that Kurlbaum's correction to his work is none too large.

Valentiner ${ }^{5}$ undertook the work anew and found quite different values, depending upon the blackness (kind) of radiators employed, which were heated as high as $1450^{\circ}$. For the two blackest radiators (the steam-heated radiator "W. S. K" and the electrically heated unblackened porcelain tube radiator "G. S. K") he found a value of $\sigma=5.36$.

In a note replying ${ }^{6}$ to Paschen's criticisms of the bolometric method he made a correction of about 4 per cent for various causes (e. g., I per cent for lack of blackness of the radiator, 2.5 per cent for reflection from the bolometer, etc.) which gives him a value of $\sigma=\mathbf{5 . 5 8}$.

It is rather singular that the correction for atmospheric absorption is entirely overlooked by all those who entered into the,

\footnotetext{
${ }^{8}$ Kurlbaum, Verh. Phys. Gesell., 14, p. 576; rgra.

${ }^{4}$ Coblentz, J. Franklin Institute, p. 549, Nov.; rgr2. This Bulletin, 9, p. 283; rgr3.

5 Valentiner, Ann. der Phys., (4), 31, p. 272; 1910.

6 Valentiner, Ann. der Phys., (4), 39: p. 489, 1912; 41, p. ro59; r9r3.
} 
rather controversal, discussion of these measurements. The numerical values of the various determinations made by Valentiner, upon any one radiator, have a range of about 3 per cent, which was usually higher than allowable in order to ascertain the effect of atmospheric absorption in a space of 30 to $50 \mathrm{~cm}$. However, when using a larger porcelain tube radiator ${ }^{7}$, "G. S. K.," the distances were rather longer than usual, being, respectively, 89 and $\mathrm{I} 25 \mathrm{~cm}$, and the effect of absorption seems unmistakable. The value of the radiation constant is about 2 per cent smaller for the greater distance, i. e., an increase of $35 \mathrm{~cm}$ in optical path introduced an absorption of about 2 per cent. It is difficult to say how great a correction should be applied to Valentiner's values in order to eliminate atmospheric absorption. The observations were made in the winter, when the humidity was, no doubt, much lower than for the tests given on a subsequent page, where an absorption of over 5 per cent was found in an air path of $124 \mathrm{~cm}$, the temperatures of the radiator being of the same order as used by Valentiner.

From the experiments to be described presently, it appears that the correction of I per cent for lack of blackness of the radiator seems to be well taken, while the correction of 2.5 per cent for reflection from the bolometer is probably I per cent too high. For the steam-heated radiator "W. S. K." the correction for atmospheric absorption would, no doubt, be higher than for the porcelain radiator "G. S. K." A conservative estimate of the total correction to Valentiner's original data is 5 to 6 per cent, of which amount about 3 per cent is the estimated absorption by atmospheric water vapor and carbon dioxide. This increases Valentiner's value to $\sigma=5.65$ with a possibility of the value being as high as $\sigma=5.7$, which is in remarkably close agreement with the various determinations made by other methods.

The following method is not exactly bolometric in principle but it may as well be considered here since its virtues have been under rather animated discussion in connection with the results obtained by the bolometric methods just mentioned. Gerlach ${ }^{8}$ working in the laboratory of Prof. Paschen has recently determined the con- 
stant of total radiation, $\sigma$, by a modification of Ångström's electric compensation pyrheliometer. In the original pyrheliometer of Ångström ${ }^{9}$ there are two thin, narrow, sheets of manganin to each of which is attached one junction of a thermoelement which is joined through a galvanometer. One of these manganin strips is exposed to solar radiation. Through the other manganin strip is passed an electric current of such strength that the manganin strip is heated to the same temperature as is the strip which is exposed to solar radiation. The equality of temperature is indicated when there is no current flowing through the galvanometer. Various instruments which have been tested show wide variations ( 5 to 30 per cent) in the value of the solar constant. Recent improvements, however, have produced a more reliable instrument.

In the instrument as used by Gerlach there is but one strip of manganin which is o.or $\mathrm{mm}$ in thickness, and 2 to $4 \mathrm{~mm}$ wide (length 2.7 to $3 \mathrm{~cm}$ ). At the back of this manganin strip and close to it was a thermopile of 45 elements (joined through a galvanometer) which is heated by radiation from the manganin strip, thus differing from Ångström's device in which a single thermojunction was heated by conduction from the manganin strip. The idea of using many junctions was to integrate over the whole strip, thus eliminating any irregular heating due to inequalities in the thickness of the manganin strip which was blackened electrolytically with platinum black. This manganin strip was heated electrically to the same temperature as that attained by the strip when exposed to the radiation from a black body, which was heated by steam. From a knowledge of the resistance of the strip and the electric current it was possible to determine the watt input, and hence the value of the radiation constant.

Gerlach experienced some difficulty in determining when he had exact compensation when heating the receiver electrically and radiometrically. Covering the sides of the receiver with knife-edged slits had no effect upon the radiation constant; but shielding the ends of the manganin strip from radiation caused the value of $\sigma$ to increase to a constant value, when the shields covered $1.5 \mathrm{~mm}$. or more of the ends of the strips. This is caused 
by heat conduction from the receiver to the heavy copper electrodes. In practice he exposed the whole length of the receiver to radiation, claiming that the heat conducted from the ends is the same when the metal strip is heated radiometrically and electrically. In the instrument used in the first part of the present investigation ${ }^{10}$ this difficulty was eliminated by placing the potential terminals upon the receiver, and at some distance from the heavy electrodes.

The mean value obtained by Gerlach is $\sigma=5.803$. He made no correction for losses by reflection ( 2 per cent). This was done by Paschen, ${ }^{11}$ who gives the value of $\sigma=5.9$.

Gerlach's value is based upon the determinations made with four receivers, the individual values of which depend somewhat upon the receiver, as was observed in the present work. No attempt was made to remove the atmospheric water vapor from the space between the radiator and the receiver. There is a systematic decrease of I to 2 per cent in the radiation constant for an increase of 32 to $42 \mathrm{~cm}$, in the distance of the receiver from the radiator. An appreciable absorption by atmospheric water vapor is to be expected in view of the fact that the radiator was heated to only $100^{\circ} \mathrm{C}$, which produced radiations easily absorbed by water vapor.

The work of Gerlach aroused considerable discussion among experimenters previously engaged on this same problem. This brought forth a very considerable amount of laborious experimental work by Gerlach ${ }^{12}$ in defense of his method, in which he showed that his apparatus gave'the same values as when he operated it by the bolometric method employed by Kurlbaum.

Puccianti ${ }^{13}$ proceeded to determine the constant of total radiation by a method which is just the opposite from the usual mode of operation; and, because of the small radiant energy exchanges involved, in comparison with the transfer of energy by heat conduction and by convection, this may be the weak point in his method.

10 This Bulletin, 12, p. 503 ; 1916 .

11 Pashen, Ann. der Phys., (4), 38, p. 30 ; I9r2.

12 Gerlach, Ann. der Phys., (4), 40, p. 701; 41, p. 99; 42, pp. II63, Iт67; I9г3.

13 Puccianti, Nuovo Cimento, (6) 4, p., 31; 1912. 
He constructed a bolometer in the form of a black body, which is kept at room temperature. This black body really is the radiator. The other black body (which is really the receiver), instead of being at a higher temperature, as usually is the case, is at the temperature of carbon dioxide snow or of liquid air. He measured the electric power which had to be supplied to the first black body to keep the temperature constant in order to compensate for the energy lost by radiation to the second black body. He very ingeniously constructed two black-body bolometer branches exactly alike, the one to be exposed to the cold receiver and the other to be protected from it. Each of these bolometer branches consisted of a vessel of $0.1 \mathrm{~mm}$ sheet copper having the form of a cone and a frustrum of a cone united at the bases. The lengths were $12 \mathrm{~cm}$; the maximum internal diameter was $+\mathrm{cm}$. The internal surface was smoked. The external surface was polished and upon it was wound two thin insulated wires. One of these wires, of iron, formed the bolometric branch, and the other wire, of manganin, was used as a heating resistance. The other two branches of the bolometer bridge were formed of resistance coils and the whole was connected with a galvanometer and storage battery as in' any ordinary bolometer. The two sensitive black-body branches of the bolometer were in an evacuated vessel which was kept in a tank of water.

The receiver was a blackened glass bulb. immersed in liquid air, and the bolometer was allowed to radiate to this receiver. Puccianti measured the (electrical) energy necessary for compensation to prevent the bridge from being unbalanced when one branch was exposed to the receiver. He obtained a value of $\sigma=5.96$.

The method is an ingenious variation from the usual procedure. The apparatus should have been constructed so that both bolometer branches could have been used as radiators. From the illustrations it appears that radiation from one branch could fall upon the other which would introduce errors. Tests might have been made to determine whether the bolometer remained balanced when a heating current was applied to both branches, without allowing one branch to radiate to the receiver. Furthermore, to 
repeat the herein oft-mentioned device, a heating coil should have been inserted temporarily within the radiator to determine the energy input as compared with the energy input required in the outer heating coils in order to maintain a balance.

\section{THE THERMOMETRIC METHOD WITH "BLACK" RECEIVERS}

In order to eliminate the question of reflection from the surface Féry " made a series of determinations of the radiation constant, $\sigma$, by means of a thermojunction which is formed into a long conical-shaped metal receiver which is blackened on the inside. On the outside of the cone, and insulated from it, was wound a heating coil of known resistance for calibrating the receiver. This was done by noting the temperature rise (galvanometer deflections) with the energy input, in watts. The receiver was then exposed to an electric furnace which was heated to various temperatures from 500 to $1200^{\circ} \mathrm{C}$, and the corresponding galvanometer deflections were observed. $\mathrm{He}$ obtained a value of $\sigma=6.30$.

The work was undertaken anew by Féry and Drecq, ${ }^{15}$ the receiver being a cone of brass having an opening of $30^{\circ}$ placed within a large sphere of brass which was surmounted by a glass tube with a capillary $\mathrm{I} \mathrm{mm}$ in diameter. The large brass sphere was filled with alcohol, the whole forming a thermometer in which I $\mathrm{mm}$ rise in height of the column in the capillary indicated a rise in temperature of $0: 005$. Surrounding the outside of the brass case was a coil of wire through which an electric current was passed and the watt input noted to cause the same temperature as that produced by exposing the opening of the cone to the radiator. They found a mean value of $\sigma=6.51$. 'This is the highest value yet obtained. The relative values obtained with the instrument show a fair constancy over the whole temperature range which extended to the melting point of gold. However, the same is true of Valentiner's values determined by the bolometric method. This indicates that there is some constant factor which is not eliminated and which causes a high or a low valuc. Various suggestions have been made as to the cause of their

"IF́ry, Compt. Reudus, 148, p. 915; 1909.

is Firy and Dreca, Jous. de l'hy's. (s), 1, p. 551; 1911. 
excessively large values. It appears that part of the difficulty lies in the unsymmetrical way in which the instrument is operated. It is calibrated by a heating coil which is in contact with the alcohol (or air, in the first case) and can warm the latter by conduction and by absorption of radiant energy. On the other hand, the incoming radiation must be transformed by absorption in the cone and then reaches the alcohol principally by conduction. As frequently mentioned in this paper, the weak point lies in not having the heating coil within the receiver, which should be so constructed that but little, if any, of the entering radiation, or the energy radiated from the heating coil, can escape through the opening in the receiver. This might easily have been done by forming the receiver into a double-coned receiver, such as was used by Puccianti.

A further determination of this constant was made by Féry and Drecq ${ }^{16}$ by a method which is somewhat similar to the one used in the present paper. The radiations from an electric furnace fell upon a strip of platinum (area 36 by $55 \mathrm{~mm}$ and 0.03 $\mathrm{mm}$ in thickness), blackened electrolytically with platinum black. Instead of measuring the rise in temperature by means of a thermopile, as was done in the present paper, they sighted upon the front and the rear surfaces of the platinum strip by means of a Féry pyrometer, the angle of incidence being $48^{\circ}$. Their new value of the radiation constant is $\sigma=6.2$. The measurements upon the posterior surface lead to the value $\sigma=5.57$, which is said to correspond with the measurements on the anterior surface made with plane receivers. If we correct the latter value by 2 per cent for reflection, ${ }^{17}$ we obtain the value $\sigma=5.68$, which is of the same magnitude as observed by the writer. This new determination of $\sigma$ by Féry and Drecq appears to have been made defective by their reduction of the original observations; for example, they claim that the coefficient of absorption of the receiver was only 0.82 to 0.84 , which seems impossible from numerous and diverse experiments on the diffuse reflecting power of platinum black made by others. Attention was called to this

${ }^{16}$ Féry and Drecq, Compt. Rend., 155, p. x239; x912.

17 This Bulletin, 9, p. 283; r9r3.

$37703^{\circ}-16-6$ 
fact by Bauer, ${ }^{18}$ who places their value of $\sigma$ between 5.1 and 5.8, and, by making a correction of 2 per cent for reflection, deduced a value of $\sigma=5.68$. In all three methods the data are meager as to elimination of the various errors which may occur. For example, as noted in a previous paper, ${ }^{19}$ a source of error may arise in determining the power put into the platinum strip used in the last method. Another important source of error lies in the manner of operation of the water-cooled shutter, which should be placed between the water-cooled diaphragm and the radiator.

In order to obviate the difficulties encountered by Féry and Drecq in calibrating their conical-shaped receivers, Bauer and Moulin ${ }^{20}$ calibrated their receiver (which was a Féry pyrometer) by sighting it upon a strip of platinum which was heated to different temperatures by an electric current. In order to determine the amount of radiant energy falling upon the receiver it was necessary to eliminate the losses from the strip by conduction and convection. For this purpose the platinum strip was heated in air and in a vacuum, the power consumed being determined for a definite length of platinum, defined by potential terminals as used in the present paper. Having calibrated the pyrometer by noting the galvanometer deflections for the various amounts of energy (in watts) put into the platinum strip, they sighted the pyrometer upon a black body heated to various temperatures and noted the galvanometer deflections. Their first announced value was $\sigma=6.0$. However, as in numerous other cases herein cited, they introduced errors in the final reduction of their data. They had observed the radiation emitted from the platinum strip at an angle of $13^{\circ}$ from the normal and applied a correction $^{21}$ of about 12 per cent which reduced their value to $\sigma=5$.3. This correction is recognized to be much too large, ${ }^{22}$ so that their value of the radiation constant lies between $\sigma=\mathbf{5 . 3}$ and 6.0 , which indicates the close grouping of all the determinations about the value $\sigma=5.7$. They made no correction for atmospheric absorption which would increase their value from $\sigma=5.3$

\footnotetext{
18 Bauer, Soc. Franc. de Phys., Proces Verbeaux, No. 4r; 1913.

19 This Bulletin, 12, p. 503; rgr6,

${ }^{20}$ Bauer and Moulin, Compt. Rend., 149, p. 988 ; 1909 . Bull., Seances Soc. Fr. de Phys., p. 58; 19ro.

21 Bauer and Moulin, Compt. Kend., 150, p. 167; xو10.

22 Bauer, Soc. Fr. de Phys., Proces Verbaux, No. 4I; I9r3.
} 
to $\sigma=\mathbf{5 . 6}$ or 5.7. In a previous communication on the solar constant Bauer and Moulin, ${ }^{23}$ using an Ångström pyrheliometer, found the value $\sigma=\mathbf{5 . 7}$.

Puccianti ${ }^{24}$ gives a determination in absolute measure of the radiation of a black body in which the temperature change is measured by means of a toluene thermometer, the bulb of which is formed into a hollow cone that is allowed to radiate to a blackbody receiver, which is at the temperature of liquid air. The measurement is made by compensating the heat lost by the thermometer by the application of an electric current.

The apparatus not being differential in construction, the temperature of the water bath had to be kept rigorously constant in order to have the meniscus of the thermometer move slowly and regularly. The response of the apparatus was, of course, slow and sluggish, which is a common property of this type of receiver (radiator), so that it required from four to eight minutes to obtain a measurement.

The same criticisms apply to this instrument that have been mentioned in the cruder form of thermometer used by Féry. ${ }^{25}$ The energy for compensation is supplied by a heating coil which is in contact with the liquid (a good scheme in so far as it applies to heating the liquid) and on the side of the wall of the receiver opposite to that upon which the incoming radiations impinge. The arrangement is therefore unsymmetrical. The heat of compensation should have been supplied by a coil inserted within the receiver, provision being made that little or none could escape by reflection and by direct radiation through the opening. In this manner the condition of heat interchanges would have been the most closely fulfilled. In the instrument as used the opportunity for escape of energy seems greater, so that in compensation there is a tendency to produce a value which is higher than the true value for radiation unaccompanied by conduction. By placing the heating coil within the receiver and using a high temperature radiator, Puccianti's device should be applied in the manner recently used by Keene. 
Puccianti considered the precision of this method as high as that of the bolometric apparatus, but the sensitivity of the thermometric apparatus was very much inferior to the bolometer. Nevertheless, he seems to prefer the thermometric method in spite of its small sensitivity. He succeeded in assigning a value of $6.00<\sigma<6.3$, and his intermediate value is $\sigma=6.15$.

The most recent determination of the constant, $\sigma$, is by Keene. ${ }^{28}$ The radiator consisted of an electric furnace which could be heated to $1000^{\circ} \mathrm{C}$. The receiver consisted of a hollow spherical doublewalled thermometer bulb provided with a small aperture in its side to admit the radiation to be measured. The space between the walls is filled with aniline, which served as thermometric substance, its expansion being observed in a capillary tube in the usual way, I $\mathrm{mm}$ division $=0.0005^{\circ} \mathrm{C}$.

In order to eliminate the effect of the variation of room temperature, two such thermometers were used differentially, radiation being admitted into one of them, the differential effect giving a measure of the energy supply. The interior of the bulb receiving the radiation was provided with an electric heating coil for the purpose of calibration. His value of the radiation constant is $\sigma=5.89$.

\section{INDIRECT AND SUBSTITUTION METHODS.}

Shakespear ${ }^{27}$ obtained the constant, $\sigma$, by a method which is based upon the principle that a heated body in air, in surroundings at a lower temperature, losses heat $(a)$ by conduction, $(b)$ by convection, and $(c)$ by radiation. If the rate of loss by a body be observed in two cases, the only difference being that the emissivity of the radiating surfaces varies, other conditions remaining the same, it is quite correct to assume that the losses $(a)$ and (b) will be the same and that the difference between the observed rate of loss of energy in the two cases is due only to the difference in the losses by radiation. If, now, these two different surfaces, at the temperature of boiling water, be exposed in turn to a radiomicrometer at the room temperature, we get the ratio of the rates of the energy radiated by the two surfaces.

${ }^{26}$ Keene, Proc. Roy. Soc., 88 A., p. 49; 19r3. London Electrician, 70, p. 541; 1912.

27 Shakespear, Proc. Roy. Soc. London, 86 A, p. r8o; r912. 
In the experiments a plate of metal with a silvered surface was heated electrically to $100^{\circ} \mathrm{C}$ and close to it was another plate, blackened with soot, which was cooled with water. Between the plates was air at atmospheric pressure. Shakespeare measured the watt input in order to maintain the plate at $100^{\circ}$ when (I) the surface of the plate was highly polished, and (2) when it was blackened. $\mathrm{He}$ measured also the ratio of the emissivities of the plate under these two conditions, using a radiomicrometer for the purpose. From this he obtained a value, $\sigma^{\prime}$, in absolute units. He then compared the emissivity of the lampblack surface at $100^{\circ}$ with that of a black body at the same temperature by means of a radiomicrometer. From this latter comparison combined with the value of $\sigma^{\prime}$ he found a value of $\sigma=5.67$.

From this description it may be noticed that the essential parts of the method differ from that of Westphal in that the radiator was a flat metal plate which was used in air instead of a vacuum and the black body, with which the emissivity of the plate had to be measured, was separate from it; while in Westphal's instrument the black body was self-contained within the metal (in the form of a cylinder) of which the emissivity of the surface had to be measured.

In this connection is to be considered the work of Todd ${ }^{28}$ who, working on the thermal conductivity of gases, obtained a value of the constant of total radiation which is somewhat lower than that of Shakespear. In his experiments on the thermal conductivity of gases, Todd used a layer of air inclosed between two parallel, good conducting plates, which were maintained at different temperatures. The colder plate, of course, receives heat by radiation and by conduction through the air from the hotter plate which is above it. Communication from the surrounding air is shut off by an insulating ring, and the two plates being close together in comparison with their linear dimensions the convection currents are eliminated. He determined the energy lost by radiation by varying the distance $x$ between the two plates and noting the corresponding variation in the quantity, $Q$, of heat passing from the upper to the lower plate. These values of $x$ and 
$Q$ when plotted form a rectangular hyperbola and the horizontal asymptote gives the value, $R$, of the radiation. The energy input was determined by a calorimetric method. In order to determine the constant, $\sigma$, he had simply to find the ratio of emissivities of the blackened plate to that of a black body at the same temperature, for which purpose a radiomicrometer was employed. The value of this ratio and the constants obtained in the main part of his experiment enabled him to compute the radiation constant which he found to be $\sigma=\mathbf{5 . 4 8}$.

An important determination of the Stefan-Boltzmann constant, $\sigma$, has recently been made by Westphal ${ }^{20}$ in the laboratory of Prof. Rubens. The experiment consisted in comparing the emissivity of a cylindrical block of copper, when it was highly polished and when it was blackened, with the emissivity of a black body at the same temperature. The novelty involved in the method is in having the black body contained within the cylinder. The copper cylinder was heated electrically, and to reduce the energy losses by gaseous heat conduction this copper cylinder was suspended in a glass flask from which the air could be exhausted to I $\mathrm{mm}$ pressure. The outer surface of the cylinder was either highly polished to give it a low emissivity or painted with lampblack to give it a high emissivity. The end surfaces remained unchanged. The heat losses by conduction and convection were therefore the same throughout the experiment and the difference in energy input, when the surface of thie cylinder had a high emissivity and when it had a low emissivity, was a measure of the energy lost by radiation.

Using the surface of the cylindrical body when highly polished, Westphal proceeded to find the curve of watt input of the body between the temperatures $35^{\circ}$ and $425^{\circ}$ absolute as a function of the temperature. Then the surface of the body was brought to a high emissivity by applying in succession different blackening materials, and the energy input was measured at different temperatures.

The emissivities of the surface and of the interior of the copper cylinder were compared by means of a thermopile. The numerous 
details need not be discussed. Suffice it to say, that the work appears to have been thoroughly done, and from the nature of the method it seems free from gross systematic errors. His mean value is $\sigma=5.54$.

He modified the original apparatus and extended the observation over a wider range of temperature with a view to increasing the accuracy. The new value ${ }^{30}$ agrees well with the earlier determination, being $\sigma=\mathbf{5 . 5 7}$.

From this summary (see Table I) it is of interest to note that the predominating values of the coefficient of total radiation cluster about a mean value of $\sigma=5.7$. In this connection it is of interest to include in this paper a theoretical computation by Lewis and Adams ${ }^{31}$ based upon the elementary electric charge, $E$, the gas constant, $R$ and the Faraday equivalent, $F$, which gives a value of $\sigma=5.7$.

\section{TABLE 1}

Observed Value and the Most Probable Value of the Radiation Constant after Correcting for Reflection, Atmospheric Absorption, etc.

\begin{tabular}{|c|c|c|c|c|}
\hline Observer & Date & $\sigma \times 10^{12}$ & $\begin{array}{c}\text { Probable } \\
\text { value of } \\
\sigma \times 10^{12}\end{array}$ & Method \\
\hline Kurlbaum ........ & 1898 & 5.45 & $?$ & Bolometer. \\
\hline Féry.............. & 1909 & 6.3 & $?$ & Thermometer. \\
\hline \multirow[t]{2}{*}{ Bauer and Moulin. } & 1909 & 5.30 & 5.7 & Thermopile. \\
\hline & 1910 & 5.7 & 5.7 & Pyrheliometer. \\
\hline Todd..... & 1909 & 5.48 & 5.48 & Gas conduction expts. \\
\hline Valentiner..... & 1910 & 5.58 & $5.65-5.7$ & Bolometer. \\
\hline Féry and Drecq... & 1911 & 6.51 & $?$ & Thermometer. \\
\hline Do $\ldots \ldots \ldots \ldots . . . .$. & 1912 & 6.2 & 5.68 & Calibrated pyrometer. \\
\hline Shakespear.. & 1912 & 5.67 & 5.67 & Ratio of emissivities, metal: Black body. \\
\hline Gerlach........... & 1912 & 5.9 & 5.9 & Modified Ångström pyrheliometer. \\
\hline \multirow[t]{2}{*}{ Puccianti.. } & 1912 & 5.96 & ? & Bolometer. \\
\hline & & 6.15 & $?$ & Thermometer. \\
\hline \multirow[t]{2}{*}{ Westphal.. } & 1912 & 5.54 & 5.57 & Ratio of emissivities, metal: Black body. \\
\hline & 1913 & 5.57 & & \\
\hline Keene.... & 1913 & 5.89 & 5.89 & Thermometer. \\
\hline Coblentz....... & 1915 & -........ & 5.72 & Modified Ångström pyrheliometer. \\
\hline
\end{tabular}

30 Westphal, Verh. d. Deutsch. Phys. Gesell, 15, p. 897; 19r3.

31 Lewis and Adams, Physical Review, (2), 3, p. 92; x914. 


\section{THE PRESENT DETERMINATION OF THIS CONSTANT}

In the foregoing pages the various methods for evaluating radiant energy in absolute measure have been summarized. Each method appears to have some merits not possessed by others. The numerical value of the coefficient of total radiation can not therefore be selected by using a method which may give a value which happens to fit closely a given theory; but it must be based upon a proper weighing of all the data at hand. It has, of course, been realized all along that the "value ${ }^{32}$ of the radiation constant is open to criticism until it has been determined with apparatus in which both the emitter and the receiver fulfill black body conditions." However, the work already done can not be brushed aside by pedantic statements of this kind. It is an easy matter to propound the conditions of operation. It is an entirely different matter to realize these conditions in practice because of the mechanical difficulties in construction. Nearly. all receivers hitherto employed, which embodied the black-body principle, have been unwieldy devices, slow in response to the stimulus; and they have been inapplicable as pyrometers for routine laboratory work. The bolometer and the thermopile, by proper calibration, can be used as a pyrometer, but one is then forced to rely upon the galvanometer unless one devises a special potentiometer outfit for measuring the heating effect, and uses a special device for a standard of radiation for testing the sensitivity of the receiver.

In the instrument used in the present investigation ${ }^{33}$ the primary receiver and the standard of radiation which is used for testing the sensitivity of the thermopile and galvanometer are incorporated in one piece. The electric power consumed in producing the same temperature within the strip as was produced by the absorption of radiant energy is measured by ordinary laboratory instruments. The loss of radiant energy by reflection from the surface of the receiver (likewise the loss by conduction from the ends, and the effect of thickness) can be determined experimentally. Conduction and convection losses of energy from the surface are assumed to be the same when the strip is heated internally as when it is heated by the absorption of radiant energy upon one surface.

${ }^{2}$ Keene, Proc. Roy. Doc., 91, p. 190; 1915.

22 This Bulletin, 12, p. 503; r916. 
From the nature of the construction of the receiver one would expect to find that it would require a smaller expenditure of energy when the strip is heated internally than when it is heated to the same temperature by heating one surface by the absorption of radiant energy. One would therefore expect that, barring experimental errors, the value of the radiation constant, determined by the present method, is smaller than the true value.

A very thick layer of lampblack, especially when present upon the front surface, should give a smaller value for the constant radiation than that observed with a thin absorbing layer. In a previous paper ${ }^{34}$ it was shown that the infra-red rays of long wave lengths penetrate the absorbing layer to a considerable depth, so that, for complete absorption, the layer of platinum black must be of considerable thickness. However, from the experiments ${ }^{35}$ given in the first part of the present investigation, it is evident that the observed value of the radiation constant can not be much too low, excepting in the case noted where the front surface had a much thicker layer of lampblack than the rear surface. An excellent example is receiver No. 7 , in which the heat capacity was increased to such an extent that it required 35 seconds to attain temperature equilibrium. The thin receivers of platinum attained temperature equilibrium in 8 to ro seconds (the delay of I 5 seconds was due to the lag in the thermopile), and although it required about four times as long to attain temperature equilibrium in receiver No. 7 , the value of the constant of radiation is not affected in a marked degree by the thick layer of material. One can therefore conclude from the experiments upon receivers varying Io times in thickness that the difference in thickness of the metal strips and of the absorbing surfaces has only a minor effect upon the radiation measurements. Although the various receivers give different values, there is a remarkably close agreement among the determinations made with any one receiver. As was observed also by Gerlach, the amount of shadowing of the receiver by the slits had an inappreciable effect upon the value of the constant.

Having eliminated the atmospheric water vapor the absorption of radiant energy was reduced. Furthermore, the distance of the receiver from the radiator was short, and it was varied from 30 
to $50 \mathrm{~cm}$. Throughout this range the value of the radiation constant was not affected by the absorption of atmospheric water vapor. However, when the water vapor was not removed the value of the constant $\sigma$ was decreased as a result of absorption of infra-red radiations of long wave lengths, as will be described in a subsequent page. Kurlbaum and Valentiner used much greater distances between the receiver and the radiator, which no doubt affected their results, as already described.

\section{CORRECTION FOR LACK OF BLACKNESS OF THE RADIATOR}

There have been discussions as to the proper dimensions of the interior of the radiator to insure completeness of emission as defined theoretically. The main difficulty with large-sized radiators, heated to a high temperature, is that they are clumsy, unwieldy devices which are slow to reach a steady temperature; and it is difficult to establish a uniform temperature throughout their interior. It has not yet been shown that there is a marked difference (if any) in the radiation constant as determined from measurements upon a large-sized radiator (heated by a steam bath) and a small-sized, blackened, tubular, porcelain radiator of the Lummer-Kurlbaum type, heated to $1000^{\circ} \mathrm{C}$ or higher. The work of Valentiner seems quite conclusive on this point. For the calibration of optical pyrometers and for radiation work in general the tubular form of radiator is the most applicable instrument yet devised. It is therefore desirable to determine the correction for lack of blackness of such a radiator. In a previous paper ${ }^{36}$ it was found that the constant of spectral radiation from painted and unpainted porcelain radiators was the same, indicating that the radiator had the properties of a "gray body" even if it did not fulfill the condition of a theoretically complete radiator. The experiments, about to be described, show that the radiations from a blackened porcelain tube radiator approach very closely to the theoretically complete radiator.

The coefficient of total radiation was determined for a new unpainted Marquardt porcelain radiator and for the blackened radiator, prepared as described in the paper just quoted. Both radiators were heated radiometrically by means of the outer heat- 
ing coil described in the paper just quoted. In this manner the new unpainted porcelain radiator did not require winding with platinum ribbon. In the unblackened radiator the front thermocouple was bare along the line of contact across the radiating surface which had a reflecting power of about $5^{8}$ per cent. (See Table $3{ }^{37}$.) The value of the constant differs, if at all, by less than I per cent from that observed with the blackened radiator, as may be seen from Table 2 .

TABLE 2

\section{Difference in Emissivity of an Unblackened and a Blackened Radiator}

[Receiver No. 11 (length=22.389 mm, width $=6.481 \mathrm{~mm})$; diaphragm No. $3(\mathrm{~d}=3.987 \mathrm{~mm})$; excellent coating of platinum black]

\section{UNPAINTED RADIATOR}

\begin{tabular}{|c|c|c|c|c|}
\hline \multirow{2}{*}{ Series } & \multirow{2}{*}{ Distance } & \multicolumn{2}{|c|}{ Temperature } & \multirow{2}{*}{$\begin{array}{l}\text { Coefficient } \\
\text { of } \\
\text { radiation, } \\
\sigma \times 10^{12}\end{array}$} \\
\hline & & $t_{0}$ & $t_{1}$ & \\
\hline & $\mathrm{mm}$ & ${ }^{\circ} \mathrm{C}$ & ${ }^{\circ} \mathrm{C}$ & \\
\hline \multirow[t]{3}{*}{ CXIVIII. } & 377.0 & 15.5 & 1078.0 & 5.572 \\
\hline & & & .1 & .566 \\
\hline & & & .3 & .572 \\
\hline \multirow[t]{3}{*}{ CXLIX.. } & 419.4 & 16.0 & 1078.7 & 5.592 \\
\hline & & & .7 & .591 \\
\hline & & & .7 & .603 \\
\hline \multirow[t]{3}{*}{ CL.. } & 475.7 & 16.0 & 1078.6 & 5.557 \\
\hline & & & .4 & .560 \\
\hline & & & .2 & .565 \\
\hline \multirow[t]{2}{*}{ CLI.... } & 442.9 & 16.0 & 1078.1 & 5.569 \\
\hline & & & 7.9 & .585 \\
\hline
\end{tabular}

Mean value $\sigma=5.576 \times 10^{-12}$ watts $\mathrm{cm}^{-2} \mathrm{deg}^{-4}$.

\section{PAINTED RADIATOR}

\begin{tabular}{|c|c|c|c|c|}
\hline \multirow[t]{3}{*}{ CLII .. } & 379.8 & 17.0 & 1082.0 & 5.610 \\
\hline & & & 1.2 & .620 \\
\hline & & & .0 & .637 \\
\hline \multirow[t]{3}{*}{ CLIU. } & 417.6 & 17.0 & 1084.0 & 5. 637 \\
\hline & & & .0 & .625 \\
\hline & & & 3. 7 & .627 \\
\hline \multirow[t]{2}{*}{ CLIV. } & 446.5 & 17.0 & 1084.5 & 5. 605 \\
\hline & & & .5 & .614 \\
\hline
\end{tabular}

Mean vaiue $\sigma=5.622 \times 10^{-12}$ watts $\mathrm{cm}^{-2} \mathrm{deg}^{-4}$.

$\Delta \sigma=0.046$.

${ }^{37}$ This bulletin, 12, p. 523; 1916. 
The lack of blackness of the radiator has been discussed by Wien and Lummer, ${ }^{38}$ who give a method for computing the correction for the opening in the radiator, on the assumption that the inclosure is spherical and diffusely reflecting. The amount of energy that can escape by diffuse reflection through the opening is determined practically by the size of the opening as compared with the total area of the interior of the radiator. In the porcelain tube radiator used in the present work the interior is uniformly heated over a length of 8 to $10 \mathrm{~cm}$. However, for the purpose of the present computation, a length of only $2.5 \mathrm{~cm}$, which is defined by the first diaphragm, is considered. The diameter of the tube is $3 \mathrm{~cm}$ and that of the hole in the inner diaphragm is $2 \mathrm{~cm}$. The area of the inclosure is $37.6 \mathrm{~cm}^{2}$ and that of the opening is $3.1 \mathrm{~cm} .{ }^{2}$ On the basis that the reflecting power of the interior of the radiator is 7 per cent (see Table $3^{38}$ ) the loss of energy by diffuse reflection through the inner diaphragm is 0.63 per cent. Using the unpainted Marquardt porcelain having a reflecting power of $5^{8}$ per cent (see Table $3^{38 a}$ ), the loss of energy by diffuse reflection through the opening in the black body would be about II.5 per cent. In other words, the values of the radiation constant as determined on the blackened and the unblackened radiator should differ by about I I per cent on account of the lack of "blackness" of the unpainted radiator. This is entirely at variance with the experimental determinations, which show a difference in blackness of less than I per cent. These computations are, of course, open to criticism because the inclosure is not spherical. However, the diffuse reflection and emission within a cylindrical inclosure can hardly differ from that of a spherical inclosure by an amount indicated by the computations. Furthermore, these computations are based upon reflecting power data obtained at room temperature. There are good reasons for believing that the reflecting power of porcelain and especially of (the black) oxides decreases with rise in temperature; for it is well known ${ }^{39}$ that their total emissivity increases with rise in temperature, that they become better electrical conductors, that their emission spectra become

\footnotetext{
28 Wien and Lummer, Ann. der Phys., (3), 56, p. 450; 1895 .

38 This bulletin, 12, p. 523; 19r6.

20 See recent papers by Randolph and Overholzer, Phys. Rev., (2), 2, p. I44, I9r3; by Burgess and Foote, this bulletin, 11, p. 41, 1914; and by Foote, this Bulletin, 11, p. 607, 1915.
} 
more continuous, etc. All these factors ${ }^{40}$ indicate a decrease in internal reflection and hence a decrease of the diffuse reflection approaching a value of about 4 per cent, which is the average reflectivity of a plane surface of a vitreous substance. The measusements made by Rubens ${ }^{41}$ on a gas mantle, when cold and when heated to incandescence, show a marked decrease in reflecting power with rise in temperature. This is an extreme case in which but little change in reflectivity is to be expected in view of the fact that the electrical conductivity of the gas mantle increases but little with rise in temperature.

From the foregoing it appears that the correction, if any, for lack of blackness of the radiator used in this work is not greater than 0.5 per cent. In other words, the mean value of the radiation constant is to be increased by 0.03 per cent, which is less than the range in the values of the various measurements due to experimental errors and due to variation humidity.

\section{CORRECTION FOR ATMOSPHERIC ABSORPTION}

The amount of carbon dioxide in the atmosphere is sufficient to produce an appreciable absorption in the spectral regions at 2.7 , 4.2 , and $14 \mu$. Water vapor has a much greater absorption than $\mathrm{CO}_{2}$ throughout the spectrum from $\mathrm{x} .4$ to $100 \mu$. A radiator heated to $1000^{\circ}$ emits more strongly radiations of all wave lengths throughout the infra-red spectrum to Ioo $\mu$, and consequently the effect of atmospheric absorption becomes appreciable even at a distance 30 to $40 \mathrm{~cm}$ from the radiator.

In the present investigation the air path between the receiver and the radiator was inclosed and the water vapor was removed by means of phosphorous pentoxide. Most of the observations were made in February and March, when the humidity was low. The drying material was placed in the inclosure the evening preceding the day the observations were made, and the following morning it would be found that but little of the phosphorous pentoxide had been affected by the moisture, showing that the moisture had been eliminated. However, the tests now to be described were made in June, when the vapor pressure was high, and the phosphorous pentoxide placed in the inclosure in the

40 This bulletin, 4, p. $533 ; 5$, p. $159,1908$.

4l Rubens, Bull., des Seances Soc. Franc. de physique; rgo6. 
evening preceding the test was found entirely dissolved the following morning. The radiation constant determined then with a certain receiver (No. $\mathrm{x} 2$, series CLXXIV et seq., Table 3) was much lower than observed when the humidity was lower. It is therefore concluded that although fresh drying material was provided about an hour before beginning observations there was sufficient moisture present to affect the value of the radiation constant. This is well illustrated in Table 3 , series CLXXX (and in Table 5, series CLV to CLXII, given in this bulletin, I2, p. 540).

As already mentioned, when the moisture was removed from. the intervening space between the radiator and the receiver the radiation constant was independent of the distance. This is true especially in cases where the measurements were first made at the longest distance (after the air had been dried overnight) and then the distance reduced. In cases where the measurements were made at the shortest distance, moist air would enter when increasing the distance, and the constant might be lower, owing to the fact that sufficient time had not elapsed in order to remove all the moisture.

TABLE 3

Effect of Atmospheric Moisture on the Radiation Constant

[Diaphragm No. 3; dia. $=3.987 \mathrm{~mm}$; receiver No. 12 ; area receiver $[22.385 \times 6.326]=141.608 \mathrm{~mm}^{2}$ ]

\begin{tabular}{|c|c|c|c|c|c|c|}
\hline \multirow{2}{*}{ Series } & \multirow{2}{*}{ Date } & \multirow{2}{*}{$\begin{array}{l}\text { Distance } \\
\mathrm{mm}\end{array}$} & \multicolumn{2}{|c|}{ Temperature } & \multirow{2}{*}{$\begin{array}{c}\text { Coeffi- } \\
\text { cient of } \\
\text { radiation } \\
\sigma \times 10^{12}\end{array}$} & \multirow{2}{*}{ Remarks } \\
\hline & & & $t_{0}$ & $t_{1}$ & & \\
\hline \multirow{3}{*}{ CLXXIV.... } & \multirow{3}{*}{ June 5,1915} & \multirow{3}{*}{1238.9} & ${ }^{\circ} \mathrm{C}$ & ${ }^{\circ} \mathrm{C}$ & & \multirow{3}{*}{$\begin{array}{l}\text { No tube; vapor pressure } 11.21 \\
\text { mm. }\end{array}$} \\
\hline & & & \multirow[t]{2}{*}{20.2} & $\begin{array}{r}1077.9 \\
.6\end{array}$ & $\begin{array}{r}5.328 \\
.325\end{array}$ & \\
\hline & & & & 5.4 & .359 & \\
\hline \multirow[t]{5}{*}{ CLXXV... } & \multirow[t]{5}{*}{ June 7,1915} & \multirow[t]{5}{*}{1238.7} & \multirow[t]{5}{*}{21.0} & $\begin{array}{r}1081.0 \\
.2\end{array}$ & $\begin{array}{r}5.104 \\
.114\end{array}$ & \multirow[t]{5}{*}{$\begin{array}{l}\text { No tube; vapor pressure } 14.02 \\
\text { mm. }\end{array}$} \\
\hline & & & & .3 & .213 & \\
\hline & & & & .3 & .213 & \\
\hline & & & & .2 & .209 & \\
\hline & & & & 0.9 & .239 & \\
\hline \multirow[t]{8}{*}{ CLXXXVI.. } & \multirow[t]{8}{*}{..... do ........ } & \multirow[t]{8}{*}{1238.7} & \multirow[t]{8}{*}{21.1} & 1077.7 & 5.178 & \multirow{8}{*}{$\begin{array}{l}\text { No tube; Thermopile lowered } \\
1 \mathrm{~cm} \text { below optic axis. }\end{array}$} \\
\hline & & & & .9 & .185 & \\
\hline & & & & .8 & .218 & \\
\hline & & & & .4 & .180 & \\
\hline & & & & .4 & .189 & \\
\hline & & & & .2 & .213 & \\
\hline & & & & .2 & .196 & \\
\hline & & & & .3 & .198 & \\
\hline
\end{tabular}


TABLE 3-Continued

\begin{tabular}{|c|c|c|c|c|c|c|}
\hline \multirow{2}{*}{ Series } & \multirow{2}{*}{ Date } & \multirow{2}{*}{$\begin{array}{l}\text { Distance } \\
\mathrm{mm}\end{array}$} & \multicolumn{2}{|c|}{ Temperature } & \multirow{2}{*}{$\begin{array}{l}\text { Coeffi- } \\
\text { cient of } \\
\text { radiation } \\
\sigma \times 10^{12}\end{array}$} & \multirow{2}{*}{ Remarks } \\
\hline & & & $t_{0}$ & $t_{1}$ & & \\
\hline & & & ${ }^{\circ} \mathrm{C}$ & ${ }^{\circ} \mathrm{C}$ & & \\
\hline \multirow[t]{6}{*}{ CIXXVII... } & June 7,1915 & 503.8 & 21.1 & 1076.1 & 5.423 & No tube. \\
\hline & & & & 5.9 & .407 & \\
\hline & & & & .8 & .441 & \\
\hline & & & & .7 & .438 & \\
\hline & & & & .8 & .453 & \\
\hline & & & & .8 & .437 & \\
\hline \multirow[t]{4}{*}{ CLXXVIII.. } & .....do ........ & 356.6 & 21.0 & 1075.3 & 5.509 & Do. \\
\hline & & & & .1 & .499 & \\
\hline & & & & 4. 7 & .512 & \\
\hline & & & & .7 & .512 & \\
\hline \multirow[t]{6}{*}{ CLXXIX.. } & June 9,1915 & 521.2 & 25.5 & 1081.7 & 5.496 & With tube; drying material \\
\hline & & & & .7 & .512 & (in 30 minutes). \\
\hline & & & & .6 & .526 & \\
\hline & & & & .7 & .531 & \\
\hline & & & & .7 & .537 & \\
\hline & & & & .9 & .538 & \\
\hline \multirow[t]{8}{*}{ CIXXX.. } & .....do. & 521.2 & 25.2 & 1082.4 & 5.535 & With tube; drying material \\
\hline & & & & .3 & .543 & (in 2 hours). \\
\hline & & & & .4 & .544 & \\
\hline & & & & .1 & .564 & \\
\hline & & & & .1 & .532 & \\
\hline & & & & 1.9 & .558 & \\
\hline & & & & 2.0 & .550 & \\
\hline & & & & .1 & .534 & \\
\hline \multirow[t]{4}{*}{ CLXXXI.. } & .....c. ... & 521.2 & 25.2 & 1082.3 & 5.419 & No tube. \\
\hline & & & & .5 & .419 & \\
\hline & & & & .5 & .415 & \\
\hline & & & & .5 & .421 & \\
\hline \multirow[t]{6}{*}{ CLXXXII... } & .....do .... & 521.2 & 25.2 & 1073.2 & 5.408 & With tube; no arying mate- \\
\hline & & & & .4 & .448 & rial. \\
\hline & & & & .3 & .412 & \\
\hline & & & & 2.8 & .396 & \\
\hline & & & & .6 & .391 & \\
\hline & & & & 3.0 & .379 & \\
\hline CLXXXIII.. & .....do ........ & 521.2 & 25.2 & 1072.6 & 5.445 & No tube. \\
\hline & & & & 2.7 & .420 & \\
\hline & & & & 3.0 & .399 & \\
\hline & & & & .0 & .415 & \\
\hline & & & & .1 & .411 & \\
\hline
\end{tabular}

The measurements of the radiation constant through humid air are given in Table 3. The receiver was aligned in front of the water-cooled diaphragm by means of a long, straight, especially 
prepared brass tube, as described in the previous paper. ${ }^{42}$ However, fearing that the vapors from the blackened diaphragms within this tube might affect the results, the connecting tube was removed after making the alignment. The measurements are therefore somewhat affected by air,currents on the thermopile. On June 5 (see Table 3 ) the air temperature was $2 \mathrm{I}_{4}^{\circ} \mathrm{C}$ and the vapor pressure was II.2I $\mathrm{mm}$. The weight of water was, therefore, II grams per cubic meter. The next day the air temperature was $22: 6$ and the vapor pressure was $14.05 \mathrm{~mm}$, equiva lent to 13.7 grams of precipitable water per cubic meter. For this higher vapor pressure the radiation constant (series CLXXV) is about 2 per cent lower than that observed through a lower vapor pressure. The same result was obtained after lowering the receiver $\mathrm{I} \mathrm{cm}$ below the axis of the rays showing that the alignment was not at fault. Decreasing the distance from $124 \mathrm{~cm}$ to $36 \mathrm{~cm}$ increased the radiation constant from $\sigma=5.21$ to $\sigma=5.51$, i. e., almost 6 per cent. Further tests were made with and without the inclosing tube (series CLXXXI to CLXXXIII) to show that there was no reflection from the inclosure. This showed that the lower value for the radiation constant, observed when the moisture was not removed, is due to the presence of water vapor. This is well demonstrated in series CLXXIX, which gives the value of $\sigma=5.496$, after the air had been dried for about one-half hour and the gradual increase in this value, with each new determination, to $\sigma=\mathbf{5 . 5 3 8}$ at the end of another half hour. After two hours drying of the air, the value increased to $\sigma=5.55$ or an increase of 2 per cent ( $\sigma=5.41$ in air) by removing the greater part of the moisture from a column of air $52 \mathrm{~cm}$ in length. The highest value observed is no doubt still too low, because of the presence of moisture as already explained, for, in earlier observations made with this same receiver, the value was $\sigma=5.65$, or a 2 per cent higher value, which is not attributable entirely to experimental errors in readjusting the apparatus. Further data, showing the great effect of the presence of water vapor upon the value of the radiation constant, are to be found in Table 5 , receiver No. II, series CLV to CLIXII, given in this Bulletin 12, p. 540, 
in which there is a variation of 2 to 3 per cent, depending upon the presence of moisture.

The data at hand indicate conclusively the serious effect of the presence of water vapor upon radiation measurements. This is, of course, not entirely new, for Tyndall (and recently Fowle) had made similar measurements. However, in the measurements of the coefficient of total radiation summarized on a preceding page, experimenters heretofore did not make any correction for atmospheric absorption which was about as large as the range ( 2 to 3 per cent) in their radiometric measurements. In the present investigation, the moisture having been removed from the optical path, the correction for absorption is negligible; although there are indications that some of the variations in the observations may be attributable to the presence of moisture in the air. From this subsidiary investigation it is quite evident that it is desirable to perform the whole radiation experiment in a vacuum. In a future paper it is hoped to contribute further to this subject, in view of the fact that the data on the radiation constant will be obtainable incidentally from measurements upon a vacuum furnace the temperature of which will be measured by means of an absolute thermopile of the type just investigated. For, as stated in the beginning of the preceding paper, the object of the investigation was the production of a radiation pyrometer suitable for refined radiometric investigations.

\section{SUMMARY}

The first part of this paper gives a summary of the methods used and the values of the constant of total radiation obtained by various observers. Corrections for losses by reflection, for atmospheric absorption, and for lack of blackness of the radiator were applied. After making these corrections to the most reliable measurements the large variations in the radiation constant have disappeared, giving a value of the coefficient which is of the order of

$$
\sigma=5.7 \times 10^{-12} \text { watt } \mathrm{cm}^{-2} \text { deg. } .^{-4} .
$$

This paper gives also the correction (about I per cent) for lack of "blackness" of the radiations from an unpainted porcelain tube $37703^{\circ}-16-7$ 
radiator and for the atmospheric absorption in $\mathrm{I} .2 \mathrm{~m}$ of air containing a determined amount of water vapor, the radiator being at about $1050^{\circ} \mathrm{C}$. The data obtained in a previous paper have been corrected for losses by diffuse reflection from the receiver and combined to give a value of the coefficient (the so-called Stefan-Boltzmann constant) of total radiation from a black body, as determined by means of an absolute thermopile of the type previously described. The correction applied to all the data for diffuse reflection is taken as being $\mathrm{I} .2$ per cent. This correction may be 0.I to 0.2 per cent too high for lampblack, but it will eliminate, in part, atmospheric absorption and the possible lack of blackness of the radiator.

Of the 13 receivers used, 3 were known to be defective, and receiver No. 4 (which was one of these 3 ) was used mainly for relative measurements on the effect of using water-cooled diaphragms having different openings. The mean value of the radiation constant (corrected by 1.2 per cent for reflection) as determined by 12 receivers and representing 348 pairs of measurements is

$$
\sigma=5.75 \times 10^{-12} \text { watt } \mathrm{cm}^{-2} \text { deg. } .^{-4} \text {. }
$$

If we exclude receivers Nos. 8 and 9, which is permissible in view of the fact that they were known to be defective, the value of the coefficient of total radiation, representing the mean of 304 pairs of determinations, is

$$
\sigma=5.72 \times \mathrm{ro}^{-12} \text { watt } \mathrm{cm}^{-2} \mathrm{deg} .^{-4} \text {. }
$$

which is but little smaller than the value obtained for all the receivers. This value is based upon the mean of all the data tabulated in Table 5 of this Bulletin, Vol. I 2, page 53 I, excepting the measurements (marked with an asterisk) in which there was no slit in front of the receiver, in which moisture was present, and in which an unblackened radiator was used. All the determinations are given the same weight in finding the mean value. Each tabulated value represents two sets of measurements, each one of which is a complete determination consisting of 5 to 10 , or more, readings when the receiver was heated electrically and when it was heated radio- 
metrically. From the data at hand it appears that the value of the radiation constant is of the order of

or

$$
\sigma=5.72 \times \text { IO }^{-12} \text { watt } \mathrm{cm}^{-2} \text { deg. }{ }^{-4}
$$

$$
\sigma=\mathrm{I} .365 \times \mathrm{IO}^{-12} \mathrm{gr}-\mathrm{cal} \mathrm{cm}^{-2} \mathrm{deg} .^{-4} \text {. }
$$

Using Planck's equation and Millikan's value of the unit electric charge, this value of the constant of total radiation indicates that the constant of spectral radiation is $\mathrm{c}=14320 \mathrm{~cm}$. $-\mathrm{deg}$.

$$
\text { WASHINGTON, July 2, I9I } 5 \text {. }^{43}
$$

${ }^{43}$ Since this paper has been written Warburg and Müller (Ann. der Phys., 48, 4ro, I915) have published a value of the spectral radiation constant which is of the order: $c=14300$. This seems to indicate a remarkable agreement between theory and experiment; especially so, in view of the great difficulties: encountered in the experimental work. 


\section{NOTE I: ON STANDARDS OF RADIATION}

The foregoing researches mark what is hoped to be the beginning of real progress in the measurement of radiant energy in absolute value, especially the determination of the mechanical equivalent of light (that is, the evolution of the visible radiations, "light," in absolute measure), which research was authorized and undertaken four years ${ }^{1}$ ago. In the meantime various subsidiary researches have been finished, including ( $I$ ) the design and construction of a spectrometer ${ }^{2}$ with triple achromatic lenses of special construction by Zeiss; (2) the investigation and construction of thermopiles and an illuminator attachment ${ }^{3}$ to the spectroscope for measuring light stimuli; (3) the investigation of the loss of radiant energy by diffuse reflection ${ }^{4}$ from the surface of the radiomater; (4) the investigation of light filters ${ }^{5}$ which absorb all the infra-red rays; (5) the selective emission ${ }^{6}$ of the mercury in quartz arc and the acetylene flame; (6) the preparation of standards of radiation ${ }^{7}$ for calibrating the radiometer in absolute measure; and recently (7) the determination of the coefficient of total radiation ${ }^{8}$ of a black body. This inclides the development of an instrument for accurately evaluating weak sources of radiant energy in absolute measure.

In the absence of reliable apparatus of sufficient sensitivity for evaluating visible radiant energy, "light," in absolute measure,

1 This Bulletin, 7 , p. 66r; I9II.

2 This Bulletin, 7, p. 243; I9II.

8 This Bulletin, 11, p. I54; r9r4.

4 This Bulletin, 9, p. 283 ; I9г3.

This Bulletin, 7, p. 655, 1911; 9, p. I10, I9r2.

${ }^{6}$ This Bulletin, 9, p. 97; 1912. For data on the acetylene flame, see this Bulletin, 7, p. 243, 1911; 9, p. 98, 1912. A further investigation was made of the energy distribution of the acetylene flame, radiating flatwise and edgewise into a mirror spectrometer and also into a spectrometer with lenses having excellent optical corrections. In a forthcoming parer new data will be given which will supercede the data previously published.

7 This Bulletin, 11, p, 87; r 14 . Copies of these radiation standards have been used since then by Nutting (Trans. Illum. Eng. Soc., 9, p. 633; 1914) and by Ives, Coblentz and Kingsbury (Pinys. Rev., 5, p. 269; 1915$)$ in preliminary measurements on the mechanical equivalent of light.

8 This Bulletin, 12, pp. 503 and $553,1916$. 
it seemed best to prepare the above-mentioned standards of radiation (consisting of seasoned incandescent lamps) by comparing their radiations with that of a black body on the assumption that the coefficient of total radiation of the latter is $\sigma=5.7 \times 10^{-12}$ watt per $\mathrm{cm}^{2}$ per degree. The foregoing research, which gave a value of $\sigma=5.72 \times 10^{-12}$, shows that the assumed value is close to the experimentally determined value of various observers.

The determination of the mechanical equivalent of light, primarily of monochromatic spectral lines, was undertaken some years ago when the problem was presented to provide standards of radiation for calibrating the radiometers which are used in evaluating light stimuli in absolute measure. These light stimuli are being used by psychologists, physiologists, and physicists in researches often involving photometric measurements. The simplest method of calibrating the radiometer would therefore seem to be to photometer and radiometer a standard spectral line of known mechanical equivalent. Then, knowing the candlepower, the energy value is known in absolute measure and by exposing the radiometer (say a thermopile) to this spectral line the instrument is calibrated for all light stimuli of which the energy value is to be determined. The above-mentioned incandescent lamp radiation standards were further investigated and restandardized recently, and used in an investigation of the mechanical equivalent of light. ${ }^{9}$ In this manner a tentative value was obtained for the relation between the candlepower and the radiation of the green mercury line. Unfortunately, through a misunderstanding as to the thickness of the absorption cells used in part of this work, some of the data are rendered uncertain by the presence ${ }^{10}$ of infra-red radiation. It is therefore not advisable to use this data for an accurate calibration of a radiometer by means of the green mercury line. However, as a check on one's work, in addition to the calibration with the incandescent lamp radiation standard, a rough test could be made with the green mercury line on the basis that $\mathrm{I} \mathrm{cp}=0.02$ watt.

\footnotetext{
Ives, Coblentz, and Kingsbury, Phys. Rev., 5, p. 269; I9r5.

10 The absorption cell was $\mathrm{x} \mathrm{cm}$ in thickness instead of the writer's specifications of $2 \mathrm{~cm}$ as given in this

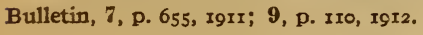


In view of the fact that the writer's investigation of the mechanical equivalent of light has been in progress for some years, and, as already stated, much of the preliminary work is already completed, the suggestion ${ }^{11}$ that this problem and the allied one of determining the visibility of radiation should be investigated at this Bureau is somewhat belated, although welcomed as indicating the demand for such data. Most of the subsidiary problems have now been worked out, excepting perhaps the question of the method of photometry. The psychologist and the physicist differ as to photometric procedure, the former claiming that the equality of brightness method of photometry is the only one that will give a true evaluation. The physicist, however, finds that the flicker method is the more precise. The main outstanding question, which involves other investigations as well as the mechanical equivalent of light, is the photometric procedure.

WASHINGTON, November 20, 191 5 . 